\title{
IMPLICANCIAS DE LA INVERSIÓN EXTRANJERA DIRECTA EN EL SECTOR MINERO DE PERÚ
}

\section{William Muñoz Marticorena}

\section{Introducción}

Q I Perú es un país líder en la minería mundial, de acuerdo con la United States Geological Survey 2004: en Latinoamérica fue el primer productor de oro, zinc, plomo y estańo. Asimismo, se ubicó entre los siete principales países productores de minerales en el mundo. Dos factores han favorecido este logro, el potencial geológico del territorio y un clima de inversión propicio.

Para comprender la naturaleza y origen del crecimiento sectorial, hay que observar los primeros años de la década del 90 , años en los que la minería peruana atravesaba una profunda crisis. La inversión de las empresas públicas mineras había prácticamente colapsado. Las inversiones cayeron de un promedio anual de US\$343 millones en el período 1980-1984, hasta US\$ 82 millones promedio anual durante 1986-90. La inversión pública minera como porcentaje del producto bruto interno (PBI) cayó desde $0,8 \%$ hasta $0,2 \%$ del PBI para los períodos en referencia.

En 1990, existía una sola empresa privada en la gran minería, Southern Peru Copper Corporation, las otras empresas (Cerro de Pasco Corporation y Marcona Mining) habían sido estatizadas por el 


\section{WILLIAM MUNOZ MARTICORENA}

Gobierno Militar en la primera mitad de la década del 70. Durante 1972-1976 la Southern realizó la última gran inversión privada en minería, aperturando la mina de Cuajone, con una inversión de US\$ 649 millones. Entre 1976 y 1990, no se realizaron inversiones de importancia. La crisis de la década del 80 habría de agudizarse debido a la guerra interna que se vivió en el país por la amenaza terrorista de Sendero Luminoso.

En noviembre de 1991, se promulgó la ley de inversiones en el sector minero, Decreto Legislativo 708, en la que se modificaba parcialmente la Ley General de Minería de 1981 (Decreto Legislativo 109). Posteriormenteb en 1992, se promulgó el Texto Único Ordenado (TUO) de la Ley General de Minería (Decreto Supremo 014-92 del Ministerio de Energía y Minas), en donde se consolidaron las normas contenidas en las dos leyes anteriores. Mediante la nueva legislación se estimuló la actividad privada en minería y se redujo la intervención y el control estaral, declarándose de interés nacional la promoción de inversiones en el sector minero y estableciéndose incentivos para los inversionistas.

Es así que en 1992, las empresas públicas mineras comienzan a ser privarizadas. Previamente, el Estado había asumido el conjunto de sus deudas de largo plazo, logrando el saneamiento financiero de las mismas. Todas las empresas se han vendido por medio de una subasta pública, definiéndose en sus bases compromisos mínimos de inversión y determinadas garantías para el Estado. En 1992, las principales privarizaciones fueron el paquete accionariado estatal en la Minera Condestable (US\$ 1 millón) y la Empresa Minera Hierro Perú (US\$ 120 millones); en 1993, se privatizaron Quellaveco (US\$ 12 millones) y Cerro Verde (US\$ 35 millones); en 1994, Tintaya (US\$277 millones) y las refinerías de zinc en Cajamarquilla (US\$ 155 millones) y cobre en Ilo (US\$ 67 millones); en 1996, Antamina (US\$ 20 millones); en 1997, la Empresa Metalúrgica de La Oroya (US\$ 122 millones) y la 


\section{IMPLICANCIAS DE LA INVERSIÓN EXTRANJERA DIRECTA EN EL SECTOR MINERO DE PERÚ}

Empresa Minera Mahr Tunel (US\$ 128 millones); en 1999, la Empresa Minera Paragsha (US\$ 62 millones); el 2002, el proyecto Alto Chicama (US\$ 2 millones); el 2004, Las Bambas (US\$ 121 millones) y, el 2005, el proyecto Bayovar (US\$ 3 millones) y La Granja (US\$ 20 millones). Todas estas privatizaciones significaron ingresos acumulados al 2005 de US\$ 1336 millones para el estado y compromisos de inversión de US\$ 6639 millones, ${ }^{1}$ la inversión acumulada entre los años 1992-2005 fue de US\$ 10355 millones.

\section{Cuadro 1: Participación Del Perú en la Producción Minera Mundial y de América Latina 2005}

\begin{tabular}{|c|c|c|}
\hline Metal & En el mundo & En América Latina \\
\hline Cobre & 3 & 2 \\
\hline Oro & 5 & 1 \\
\hline Zinc & 3 & 1 \\
\hline Plata & 2 & 2 \\
\hline Plomo & 4 & 1 \\
\hline Estaño & 3 & 1 \\
\hline Hierro & 17 & 5 \\
\hline Molibdeno & 4 & 2 \\
\hline Bismuto & 3 & 1 \\
\hline Selenio & 8 & 2 \\
\hline Teluro & 3 & 1 \\
\hline Indio & 8 & 1 \\
\hline
\end{tabular}

Fuente: U.S. Geological Survey-USGS

1 Proinversión. Oportunidades de Inversión en el Perú. Lima: Proinversión, 2006. 


\section{EL POTENCIAL MINERO DEL PERÚ}

La riqueza minera del Perú es abundante, particularmente en cobre, zinc, plata, plomo, hierro, oro y estańo, Su potencial minero es significativo: posee el $16 \%$ de las reservas mundiales de plata, el $15 \%$ de cobre, el $7 \%$ de zinc y volúmenes importantes de otros minerales.

El Perú es el séptimo país minero en el mundo, ocupa el segundo lugar en la producción mundial de plata (cuadro 1) y el tercero en cobre, zinc, estaño, bismuto y teluro, el cuarto en plomo y molibdeno. En Latinoamérica, Perú ocupa el primer lugar en oro, zinc, plomo, estaño, bismuto, teluro e indio, y el segundo en cobre, plata, molibdeno y selenio. Sin embargo, el nivel de explotación de los recursos minerales es discreto en relación al volumen de sus reservas. A finales de la década del 90 , la producción de cobre alcanzaba el $1,1 \%$ de las reservas totales; en oro se explotaba el $3,2 \%$ del total y en plata el $4,9 \%$. Las reservas medidas en función al ritmo de la producción ascendían a 200 afios en el caso del hierro, a 60 años para el cobre y a 20 y 22 años para el zinc y la plata, respectivamente.

La minería peruana realiza, asimismo, compras de bienes e insumos a la industria y el comercio local; en 1998 se compró localmente US\$ 500 millones; solo la empresa Yanacocha en el 2002 demandó US\$ 47 millones en compras locales; Antamina, en el 2002, habla efectuado compras locales por US\$ 140 millones.

Fuente: Ministerio de Energía y Minas, memorias varias. 
La contribución del sector minero a la economía peruana es importante; hacia el 2005 se exportaron US\$ 9724 millones en minerales, equivalentes al $56 \%$ de las exportaciones totales del pais. ${ }^{2}$ Considerando que hacia el 2000 se exportaban US\$ 3220 millones, al 2005 se ha logrado un incremento de $202 \%$ en las exportaciones mineras. La contribución del sector al PBI real nacional se ha incrementado de niveles de $3,4 \%$ el 2000 hasta $7,4 \%$ en el $2005 .^{3}$ La inversión en minería constituye una parte importante del stock total de inversión extranjera directa (IED) en el país. ${ }^{4}$ El $90 \%$ de la población económicamente activa (PEA) absorbida por la minería, está adecuadamente empleada (Grade); el sector absorbe, además, el $5,7 \%$ de la PEA nacional y el $27 \%$ de la PEA de la sierra.

$\mathrm{Al}$ analizar sectorialmente los impactos de las privarizaciones, observamos que fueron los sectores de telecomunicaciones y electricidad los que generaron mayores ingresos al estado por concepro de venta de empresas públicas, US\$ 3633 millones y US\$ 2864 millones respectivamente (cuadro 2 ); ${ }^{5}$ sin embargo, ha sido el sector minero el que mayores compromisos de inversión ha realizado US\$ 6639 millones (44\% del total).

2 Ministerio de Energin y Minas. Evaluación del Plan Estratégico Institucional 2004-2006. Lima: Ministerio de Energfa y Minas, 2006.

3 Banco Central de Reserva del Perú, 2006

4 Aproximadamente 15\% del total. Proinversión 2002.

5 Precios justificados en tanto las empresas privadas adquirientes accedian a un control casi monopólico del mercado nacional de estos servicios. 
Cuadro 2: Compromisos de Inversión y Transacciones por sector acumulados al 2005

uss millones

\begin{tabular}{|l|r|r|}
\hline \multicolumn{1}{|c|}{ Sector } & \multicolumn{1}{c|}{$\begin{array}{c}\text { Compromiso de } \\
\text { Inversión }\end{array}$} & \multicolumn{1}{c|}{ Transacción } \\
\hline Mineria & 6639 & 1336 \\
\hline Hidrocarburos & 2989 & 984 \\
\hline Transporles & 2701 & 94 \\
\hline Telecomunicaciones & 1576 & 3633 \\
\hline Electricidad & 781 & 2864 \\
\hline Agricultura & 243 & 46 \\
\hline Saneamiento & 153 & 0 \\
\hline Industria & 49 & 598 \\
\hline Finanzas & 30 & 421 \\
\hline Turismo & 29 & 47 \\
\hline Pesqueria & 2 & 158 \\
\hline Otros & 0 & 97 \\
\hline Total & 15193 & 10277 \\
\hline
\end{tabular}

Fuente: Proinversión

\section{Estructura del mercado}

El sector minero peruano está formado por tres tipos de empresas: las grandes, que producen más de 5000 toneladas métricas (TM) diariamente; las medianas que producen más de 350 y menos de 5000 TM por día y las pequeñas que producen menos de 350 TM diariamente, ${ }^{6}$

La mayor partedela producción está concentrada en las grandes empresas, principalmente la producción de oro, cobre y zinc. Las

6 CAMpodónico, Humberto. Las reformas estructurales en el sector minero peruano $y$ las canacteristicas de la inversión 1992-2008. Santiago: CEPAL, 1999, p. 10. 
medianas empresas producen básicamente minerales como plomo, estaño y plata.? Las pequeñas empresas mineras están reduciendo sus volúmenes de producción a lo largo de los últimos años,

En el grupo de las grandes empresas se ubican Southern Copper Corporation, Grupo México, cobre; The Doe Run, EE.UU., polimetálico; Cerro Verde, Cyprus Amax, EE.UU., cobre; Tintaya, BHP-Billiton, Australia, cobre; Shougang Corporation, China, hierro; Yanacocha, Newmont Mining (EE.UU.) y Buenaventura (Perú), oro; Antamina, Noranda, Teca y Rio Algom, Canadá, cobre y zinc; Pierina, Barrick Gold, EE.UU., oro. Realizan operaciones de extracción y concentración de minerales y algunas de ellas fundicion y refinado. Las de mayor dimensión son Yanacocha, Antamina y Southern, que explican conjuntamente más del $50 \%$ de las exportaciones mineras.

$\mathrm{La}$ mayor parte de las empresas medianas son nacionales, concentran sus operaciones en la extracción y concentración de minerales; realizan operaciones poli-metálicas y producen plata, zinc, plomo y estaño. Algunas de las principales empresas medianas son Minera Retamas, familia Marsano, oro; Minas Raura y Minsur, grupo Brescia, oro y estafío; Milpo, Baertl Montori, plomo, plata y zinc; Volcan, grupo Letts, plomo, plata y zinc; Simsa, grupo Gubbins, zinc.

La pequeña minería se caracteriza por operar en yacimientos filonianos ${ }^{8}$ y por utilizar técnicas de extracción artesanales, de baja productividad. Cada vez existen menos empresas de este ramaño, Concentran sus operaciones en la extracción de oro, particularmente, en lavaderos como los de Madre de Dios.

Las principales empresas exportadoras por tipo de producto son Minera Yanacocha, Minera Barrick Misquichilca y Procesadora

7 InstTtuto de Comercio Exterior de España, El sector de la Minería en el Perú. Informes sectoriales. Lima: Embajada de España en Lima, 2005.

8 El relleno mineral o rocoso de una grieta en otra roca más antigua. Un filón metalifero es un filón relleno de minerales. 
Sudamericana, oro en bruto; Southern, Sociedad Minera Cerro Verde, Doe Run, Consorcio Minero Cormin y BHP-Billiton Tintaya, cátodos de cobre; Compañía Minera Antamina, BHP-Billiton Tintaya y Southern, minerales de cobre y sus concentrados; Compañía Minera Antamina, Empresa Minera Los Quenuales y Volcan Compañía Minera, minerales de zinc y sus concentrados y, Southern y Companía Minera Antamina; Minerales de molibdeno,

Como consecuencia de la evolución favorable de los precios internacionales demineralesy del incrementodelacapacidad productiva interna, las exportaciones mineras durante el período 2000-2005, crecieron en $202 \%$ (cuadro 3), solamente el sector de hidrocarburos (289\%) obtuvo un crecimiento superior. Los sectores tradicionales de pesquería y agricultura crecieron $36 \%$ y $33 \%$, respectivamente. Los sectores no tradicionales con mejor perfomance en el período fueron los de agroexportación (156\%) y químicos (153\%). Factores como el Atpdea, ${ }^{9}$ el Sistema de Preferencias Generales (SPG) de la Unión Europea (EU) a los países andinos, el crecimiento sostenido de China e India, además de una agresiva promoción de exportaciones, determinaron este comportamiento favorable. Asimismo, la participación de las exportaciones mineras llegó a representar al 2005 el $56 \%$ de las exportaciones totales, 10 puntos porcentuales más que en el 2000. Durante el período 2000-2005, el producto minero que destacó fue el cobre, debido al incremento significativo de la demanda mundial y la puesta en operación de Antamina, logrando incrementar el valor de sus exportaciones en $260 \%$, (US\$ 3360 millones). Otro mineral favorecido por el incremento de su cotización fue el oro que creció en 174\% (US\$ 3140 millones) (cuadro 4).

9 Preferencia arancelaria unilateral de EE.UU. a paises andinos a fin de erradicar el cultivo de coca. 
IMPLICANCIAS DE LA INVERSIÓN EXTRANJERA DIRECTA EN EL SECTOR MINERO DE PERÚ

Cuadro 3: Exportaciones por grupo de productos 2000-2005 US\$ millones

\begin{tabular}{|c|c|c|c|c|c|c|}
\hline & 2000 & 2001 & 2002 & 2003 & 2004 & 2005 \\
\hline $\begin{array}{r}\text { Productos } \\
\text { tradicionales } \\
\end{array}$ & 4804.4 & 4730.3 & 5368.4 & 6356.3 & 9028 & 12839.4 \\
\hline Pesqueros & 954.7 & 926.2 & 892.3 & 821.3 & 1103.7 & 1302.9 \\
\hline Agricolas & 248.9 & 207.5 & 216.2 & 224.1 & 325.2 & 330.6 \\
\hline Mineros & 3220.1 & 3205.3 & 3808.9 & 4689.9 & 6953.1 & 9724.3 \\
\hline Petróleo y derivados & 380.7 & 391.3 & 451.0 & 621.0 & 646.0 & 1481.6 \\
\hline $\begin{array}{r}\text { Productos no } \\
\text { tradicionales }\end{array}$ & 2043,7 & 2182.6 & 2256.2 & 2620.5 & 3475.8 & 4270.8 \\
\hline Agropecuarios & 394.0 & 436.7 & 549.8 & 623.6 & 798.6 & 1009.4 \\
\hline Pesqueros & 176.8 & 197.0 & 163.8 & 205.0 & 277.4 & 322.1 \\
\hline Textiles & 700.7 & 664.2 & 676.7 & 823.3 & 1092.2 & 1273.7 \\
\hline $\begin{array}{l}\text { Maderas, papeles y sus } \\
\text { manufacturas }\end{array}$ & 123.0 & 142.1 & 177.1 & 172.4 & 214.3 & 258.2 \\
\hline Quimicos & 212.3 & 246.6 & 255.9 & 316.4 & 415.0 & 537.5 \\
\hline Minerales no metálicos & 46.7 & 57.7 & 68.0 & 73.5 & 94.0 & 117.5 \\
\hline $\begin{array}{l}\text { Sidero-metalúrgicos y } \\
\text { joyería }\end{array}$ & 264.8 & 242.5 & 222.4 & 262.0 & 391.5 & 492.7 \\
\hline Metalmecánicos & 96.6 & 160.0 & 109.6 & 99.4 & 134.9 & 189.8 \\
\hline Otros & 28.8 & 35.8 & 32.9 & 44.9 & 57.9 & 69.9 \\
\hline Otros & 106.7 & 112.6 & 89.2 & 114 & 113.2 & 136.9 \\
\hline $\begin{array}{l}\text { TOTAL } \\
\text { EXPORTACIONES }\end{array}$ & 6954.8 & 7025.5 & 7713.8 & 9090,8 & 12617 & 17247.1 \\
\hline \multicolumn{7}{|l|}{$\begin{array}{l}\text { ESTRUCTURA } \\
\text { PORCENTUAL }(\%)\end{array}$} \\
\hline Pesqueros & $13,7 \%$ & $13,2 \%$ & $11,6 \%$ & $9,0 \%$ & $8,7 \%$ & $7,6 \%$ \\
\hline Agricolas & $3,6 \%$ & $3,0 \%$ & $2,8 \%$ & $2,5 \%$ & $2,6 \%$ & $1,9 \%$ \\
\hline Mineros & $46,3 \%$ & $45,6 \%$ & $49,4 \%$ & $51,6 \%$ & $55,1 \%$ & $56,4 \%$ \\
\hline Petróleo y derivados & $5,5 \%$ & $5,6 \%$ & $5,8 \%$ & $6,8 \%$ & $5,1 \%$ & $8,6 \%$ \\
\hline TRADICIONALES & $69,1 \%$ & $67,3 \%$ & $69,6 \%$ & $69,9 \%$ & $71,6 \%$ & $74,4 \%$ \\
\hline NO TRADICIONALES & $29,4 \%$ & $31,1 \%$ & $29,2 \%$ & $28,8 \%$ & $27,5 \%$ & $24,8 \%$ \\
\hline OTROS & $1,5 \%$ & $1,6 \%$ & $1,2 \%$ & $1,3 \%$ & $0,9 \%$ & $0,8 \%$ \\
\hline TOTAL & $100,0 \%$ & $100,0 \%$ & $100,0 \%$ & $100,0 \%$ & $100,0 \%$ & $100,0 \%$ \\
\hline
\end{tabular}

Fuente: BCRP 


\section{WILLIAM MUNOZZ MARTICORENA}

Cuadro 4: Exportaciones de principales productos mineros 2000-2005 uss millones

\begin{tabular}{|l|c|c|c|c|c|c|c|}
\hline \multirow{2}{*}{ Exportaciones } & \multicolumn{5}{|c|}{ Valor de las exportaciones (en mill. US\$) } & \multirow{2}{*}{ Variación } \\
\cline { 2 - 7 } & 2000 & 2001 & 2002 & 2003 & 2004 & 2005 & \\
\hline Cobre & 932.6 & 985.6 & 1187.1 & 1260.5 & 2446.0 & 3360.1 & $260,3 \%$ \\
\hline Estanio & 170.2 & 149.5 & 155.4 & 211.0 & 350.7 & 264.9 & $55,6 \%$ \\
\hline Hierro & 66.6 & 81.4 & 82.9 & 94.1 & 128.4 & 211.9 & $218,2 \%$ \\
\hline Oro & 1144.7 & 1166.2 & 1500.7 & 2101.6 & 2383.1 & 3139.6 & $174,3 \%$ \\
\hline Plata refinada & 179.5 & 168.6 & 173.7 & 191.0 & 260.2 & 280.6 & $56,3 \%$ \\
\hline Plomo & 190.4 & 196.0 & 210.8 & 201.3 & 389.1 & 491.4 & $158,1 \%$ \\
\hline Zino & 495.8 & 419.4 & 428.9 & 528.7 & 576.8 & 805.1 & $62,4 \%$ \\
\hline Resto de mineros & 40.4 & 38.5 & 69.5 & 101.5 & 418.8 & 1170.6 & $2797,5 \%$ \\
\hline
\end{tabular}

Fuente: BCRP

La producción minera se orienta fundamentalmente al mercado exterior. La inversión extranjera es muy importante, especialmente en las grandes empresas. Con excepción de la participación de Minas Buenaventura (Perú) en Minera Yanacocha, se podría afirmar que las grandes empresas mineras son extranjeras. Actualmente, corporaciones líderes mundiales como Falconbridge, Barrick Gold, Xstrata, BHP-Billiton, Teca-Cominco, Mitsui, Anglo Gold, Cia Vale do Rio Doce, Newmont, Phelps Dodge, Grupo México, Cambior, Peńoles, Mitsubishi, Rio Tinto y Gold Fields; se encuentran explorando, implementando u operando minas en el territorio.

Al continuar con la descripción del mercado de minerales, debemos detenernos a observar algunas tendencias generales en el consumo. El desarrollo industrial de nuevos países demandantes de 


\section{IMPLICANCIAS DE LA INVERSION EXTRANJERA DIRECTA EN EL SECTOR MINERO DE PERU}

metales y minerales, como China, ${ }^{10}$ orienta hacia estos mercados el foco de atención de los empresarios mineros. Por otro lado, se sabe que existe una relación directa entre el desarrollo industrial y el uso de minerales. Estos factores incrementan el atractivo del mercado y lo convierten en una futura fuente de desarrollo $\mathrm{e}$ ingresos.

La demanda mundial de minerales está destinada a: la fabricación de joyería (oro y plata), al uso industrial (cobre, plomo, zinc y molibdeno), la construcción; la electrónica, odontología y la producción de lingotes (oro), medallas y monedas (plata); entre otros usos.

El oro se utiliza principalmente en la fabricación de bienes ( $80 \%$ de su demanda mundial); se estima que el crecimiento de la demanda china incremente la fabricación de bienes en dicho metal. Los principales países demandantes son India, Italia y Estados Unidos, seguidos de China, Turquía y Japón. Las perspectivas de la demanda son favorables en tanto se consolide la recuperación económica de Japón y Europa y se mantenga el crecimiento de EE.UU.

Según pronósticos de Brook Hunt, ${ }^{11}$ el consumo de cobre crecerá al 3,4\% anual durante toda la década; Leonardo Suarez ${ }^{12}$ de LarrainVial manifiesta que para el 2007 y 2008 la demanda de cobre crecerá a tasas de 4 y 5\%, generando el 2007 un déficit mundial de 107 mil toneladas y el 2008 de 514 mil. Estos desequilibrios solo podrán ser cubiertos mediante la apertura de nuevos yacimientos mineros.

La demanda por zinc vuelve a incrementarse desde el 2005, como consecuencia de un mayor consumo de acero galvanizado. Esto exigirá el desarrollo de nuevos proyectos con mayores niveles de productividad.

10 En China está surgiendo una nueva clase media que cada vez gasta más en joyas.

11 Comisión Chilena del cobre, Mercado del cobre I Trimestre 2006

12 Area minera, Abril 2006 
Las perspectivas del acero son positivas dado que satisfacen una demanda mundial en los sectores de construcción, automoción e industria manufacturera, actualmente en expansión, particularmente en el mercado chino.

La demanda nacional por minerales es reducida $y$ los eslabonamientos hacia delante con la industria nacional son débiles; se espera que la minería a futuro provea de materias primas de calidad $y$ a menor costo a una industria nacional con ventajas competitivas en determinados tipos de manufactura. ${ }^{13}$ El consumo local en relación con la producción física, asciende a $25 \%$ de zinc (electrolítico y concentrados), $10 \%$ de hierro, $8 \%$ de cobre (refinado y alambrón), $5 \%$ de plomo (refinado) y $1 \%$ de plata y oro (refinado).

La rivalidad en el sector minero, en general, no existe, debido a las características intrínsecas del sector. $\mathrm{La}$ competencia se establece a nivel internacional. Esta competencia es un estímulo para que los agentes mineros optimicen la calidad de sus productos terminados y sus servicios, innoven y reduzcan sus estructuras de costos. Podemos citar, como ejemplos de lo anterior, el caso de Yanacocha que progresivamente ha ido reduciendo el cash cost $t^{14}$ de la producción de una onza de oro, de niveles de US\$ 111 por onza en 1999 hasta US\$ 88 por onza el 2000 y el caso de Southern, que ofrece una calidad de cátodos de cobre del $99,99 \%$ de pureza, obteniendo premios internacionales.

\section{Estrategia de las firmas}

Los expertos en desarrollo señalan que la innovación es la piedra angular de la productividad. Un tipo de innovación es el cluster, o encadenamiento productivo. Este modelo ha sido empleado en muchos países desarrollados y ha comenzado a difundirse en Latinoamérica.

I3 Roca, Santiago. Inversión en el Perti 2002-2003. Lima: ESAN Ediciones, 2001. 14 Costo de Producción sin considerar el costo del financiamiento. 
Un cluster, concretamente, es la acción conjunta que realizan agentes económicos para diversos fines, sea para resolver problemas comunes, innovar o ingresar a nuevos mercados, Un cluster exitoso presenta un buen nivel de competitividad internacional.

Cristian Muñoz, experto de la Comisión Chilena del Cobre (COCHILCO), considera que se deben diseñar estrategias que involucren el desarrollo de la actividad minera y que, a partir de ella, se fortalezca al resto de sectores productivos relacionados directa o indirectamente; asimismo, señala que el cluster es una de esas alternativas.

En el Perú, existen empresas que están tratando de aplicar este enfoque. Yanacocha, por ejemplo, es una experiencia interesante, en su caso la innovación se relaciona con la presencia misma de la empresa en una zona específica de Cajamarca, que generó aglomeraciones en torno a ella y determinó el surgimiento de una economía externa. En rigor teórico, se trataría de un cluster en fase inicial enfocado más en las relaciones productivas internas de la empresa que a una interacción con los agentes externos. La efectividad del cluster o de los encadenamientos dependerá de la calidad de las relaciones de sus agentes y de la solidez del marco institucional, ambos aspectos todavía débiles en el sector minero. ${ }^{15}$

Existen tres tipos de encadenamientos que se pueden presentar en torno de la actividad minera: hacia atrás, donde se sitúan las empresas proveedoras de insumos, bienes y servicios mineros, así como los centros de investigación; laterales, que consideran a las empresas de energia, agua, gas, telecomunicaciones, construcción, entre otras; $y$ hacia delante, que incorporan las fundiciones, refinerías y empresas manufactureras.

15 De acuerdo con el informe del instituto Fraser 2005-2006, el sector minero del país en el indice de potencial de politicas cayó al lugar 44 luego de ubicarse en el puesto 39 el 2005-2004. 


\section{WILLIAM MUNOZZ MARTICORENA}

Para desarrollar una adecuada operación en zonas geográficas a más de 3500 metros de altura, se requiere no solamente organizar internamente la empresa, sino mantener relaciones apropiadas con los grupos de interés vecinos e instituciones administrativas.

El sector minero es un gran comprador de bienes y servicios, realiza compras locales por más de US\$500 millones, convirtiéndose, de esta forma, en un gran propulsor de proveedores en la mayoría de sectores económicos del país y, además, generador de empleo indirecto. Se estima que por cada empleo en la minería se crean cinco puestos en otros sectores productivos.

\section{INSTITUCIONES ADMINISTRATIVAS RELACIONADAS CON EL SECTOR MINERO}

\section{El Ministerio de Energía y Minas}

Norma, fiscaliza y promueve las actividades mineras, administra el uso racional de los recursos mineros en armonia con el medio ambiente.

\section{La Dirección General de Minería (DGM)}

Es la unidad de línea del Ministerio de Energía y Minas, depende del Despacho del Viceministro de Minas.

\section{El Consejo de Minería}

Tiene la jurisdicción administrativa en asuntos mineros al más alto nivel en la Administración Pública. Resuelve en última instancia los asuntos mineros que son materia de resolución por parte de la primera instancia administrativa. Constituyen órganos de primera instancia: la Dirección General de Minería, la Dirección General de Asuntos Ambientales, la Dirección General de Concesiones Mineras y la Jefatura del Instituto Nacional de Concesiones y Catastro Minero. 
IMPLICANCIAS DE LA INVERSIÓN EXTRANJERA

DIRECTA EN EL SECTOR MINERO DE PERÚ

El Instituto Nacional de Concesiones y Catastro Minero INACC

Tramitalas solicitudes de concesiones mineras, administra el Catastro Minero Nacional y la Administración del Derecho de Vigencia y Penalidad. Informa sobre las áreas de libre denunciabilidad.

\section{El Instituto Geológico, Minero y Metalúrgico (INGEMMET)}

Esta encargada de preparar y proveer información sobre geología regional, recursos minerales, geoambiente y minero-metalúrgica para orientar las inversiones mineras, la protección del medio ambiente y la planificación y desarrollo sostenible.

Superintendencia Nacional de Administración Tributaria (SUNAT)

Es responsable de registrar a los contribuyentes, proporcionar el certificado de Registro Único de Contribuyente (RUC). Al registrar el RUC, la empresa queda automáticamente registrada en el Seguro Social de Salud (ESSALUD) y en el Registro de Empleadores.

\section{Municipalidades}

Son las instituciones administrativas encargadas de otorgar la licencia de funcionamiento en la zona donde la empresa pretende ubicar su negocio.

\section{Proinversión}

Todas las inversiones extranjeras destinadas al capital de una empresa, así como aquellas formalizadas contractualmente en una empresa peruana, incluyendo los contratos asociativos, deben registrarse ante la Agencia de promoción de la Inversión Privada (Proinversión).

Fuente: Centrum. Análisis de la competitividad de la gran minerfametálica del Perú 


\section{PRINCIPALES SECTORES PROVEEDORES DE LA ACTIVIDAD MINERA}

- Industria química, petróleo y derivados.

- Industria siderúrgica.

- Alimentos (agricultura, pesca y ganadería).

- Industria forestal.

- Mantenimiento de maquinarias y equipos.

- Servicios de seguridad, vigilancia, limpieza, alimentación, hospedaje.

- Consultoríaen ingeniería,informática,administración, contabilidad.

- Transporte de personal, materiales, metales, concentrados.

- Construcción y montaje.

- Bancos, seguros, agentes de aduanas.

- Comercio exterior.

- Instituciones de capacitación.

Fuente: Centrum. Análisis de la competitividad de la gran mineriamecálica del Perú

La integración logística entre compañías en el sector minero pretende no solo mantener la dinámica operativa sino reducir los "sobre stocks" de materiales y repuestos. Estos se generan por la existencia de políticas de stocks de seguridad de insumos y repuestos estratégicos, por las dificultades logísticas derivadas de limitaciones en carreteras, transporte, medios de información y comunicación y por la obsolescencia tecnológica. ${ }^{16}$ En ese sentido, las principales

16 Memoria Ferreyros S. A. Lima: Ferreyros Companía, 2003. 
minas ya están introduciendo sistemas de información integral que comparten con sus principales proveedores, obteniendo con ello mejoras en la comunicación, calidad de la información y reducción de stocks y de la obsolescencia.

La minería presenta también encadenamientos productivos hacia delante, transformándose en proveedora de otros sectores; dos son sus principales productos: concentrados de mineral, que son vendidos a fundiciones y refinerías locales o entregados a traders locales o extranjeros; y los refinados, que son vendidos a empresas industriales de transformación que requieren metales para producir, cables, planchas, baterías, entre otros productos.

Las empresas extranjeras mediante fusiones y adquisiciones han reforzado su presencia en el país; las más destacadas han sido BHP-Billiton, gracias a la fusión lograron participar en proyectos como Antamina y Tintaya; Phelps Dodge que, mediante la adquisición de Cyprus Amax, accedió a la propiedad de Cerro Verde; Teck-Cominco, una fusión que permitió que estas empresas se integraran verticalmente en la producción y la refinación de zinc en Perú (Teck participa de la propiedad de Antamina y Cominco es principal propietaria de la refinería de zinc de Cajamarquilla); finalmente, Newmont-Normandy (Newmont adquirió recientemente Normandy, con lo que se ha convertido en la primera minera de oro del mundo).

Un caso exitoso de alianza estratégica con participación de una compañía peruana es Yanacocha, donde comparten la propiedad tanto la empresa norteamericana Newmont ( $51,35 \%$ de las acciones) como la peruana Minas Buenaventura $(43,65 \%)$ y la Corporación Financiera Internacional del Banco Mundial (5\%).

Las empresas extranjeras ingresaron al país mediante las privatizaciones en la década del 90 . En años recientes, el ingreso al pais de empresas extranjeras es principalmente por inversión directa. En el caso de la actividad de exploración, se han incorporado las 
empresas "Juniors", que realizan inversión de riesgo en prospección y exploración, con el propósito de descubrir yacimientos importantes que luego transfieren a empresas extranjeras o nacionales mediante su venta o coparticipación. En general, la estrategia de las empresas extranjeras ha estado orientada hacia el aprovechamiento de los recursos naturales del país mediante un despliegue de tecnología, gestión organizacional y posicionamiento en el mercado global de minerales.

Un factor relevante en la competicividad del sector es la innovación, consecuencia del nivel de investigación y desarrollo (I+D) que se realice o de la mejora tecnológica a productos y procesos que se ejecure. En el país, durante 1999-2002, la inversión en I+D de las empresas fue en promedio de solo el $0,02 \%$ de sus ventas brutas y una tendencia en las empresas a no trabajar programas de I+D. ${ }^{17}$ Según el Consejo de Ciencia y Tecnología (CONCYTEC), las empresas dan mayor importancia a la tecnologia incorporada al capital físico, a la innovación de procesos y a cambios organizacionales. El coeficiente de invención que registra el número de patentes solicitadas por residentes por cada 100000 habitantes ha descendido de 0,07 a 0,01 entre 1978 y el 2002. Por otro lado, la tasa de dependencia, que registra la cantidad de patentes solicitadas por no residentes respecto de las solicitadas por residentes, ha crecido de 4,78 a 26,6 entre 1977 y el 2002.

En ese contexto, las empresas extranjeras privilegian el mejoramiento de productos y procesos, así como la incorporación de nuevas tecnologías mediante la adquisición de nuevos activos. En la minería las áreas de interés para la innovación son minerales no merálicos, nano-materiales, recuperación de metales a partir de relaves y escorias antiguas, metalurgia extractiva de metales estratégicos, desarrollo de tecnología avanzada de fundición y refinación $y$, materiales compuestos.

17 Concrtec. Peri ance la sociedad del Conocimienro: Indicadores de CTI, 19702002. Lima: CONCYTEC, 2003. 
Los nuevos materiales industriales se basan crecientemente en productos de la minería no metálica, de los que el Perú posee un potencial importante. Cerámicos, materiales compuestos y polímeros especiales de calidad, y particularmente los nano-polvos, todos con altos precios en el mercado; sin embargo, para capitalizar estas oportunidades se requiere un importante esfuerzo de investigación y desarrollo tecnológico.

Un problema pendiente de solución en la minería es el de la gestión de residuos de la actividad minera, específicamente de los relaves. Para reducir sus impactos negativos y preservar el medio ambiente, se han implementado trabajos de lixiviación, química o biológica, y otros procedimientos de separación de materiales. Estos procesos además de ser menos contaminantes, permiten mediante la recuperación de residuos, obtener productos comercializables que generan importantes ganancias a las empresas mineras, mejorando además, la percepción de la comunidad sobre sus actividades productivas.

En los minerales exportados y en los desechos mineros, hay una importante y variada presencia de metales estratégicos (Cd, Mo,

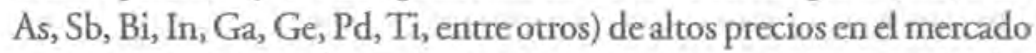
internacional. Sin embargo la poca investigación que se realiza sobre los materiales extraídos de las minas, impide su completa caracterización $\mathrm{y}$ aprovechamiento económico. Este trabajo de investigación demanda la introducción de tecnologías avanzadas de fundición y refinamiento. En tiempos recientes, se han dado grandes cambios en la tecnología minera. Este avance posibilita la transformación de los minerales y metales en materiales con propiedades compatibles con las nuevas exigencias de uso. En particular, existen materiales compuestos que pueden ser elaborados a partir de minerales metálicos y no metálicos nacionales. 
Los programas de exploración incorporan actualmente mejoras tecnológicas como las imágenes satelitales para identificar zonas a explorar, las operaciones a tajo abierto, de bajo costo de inversión y operación (como los procesos hidrometalúrgicos y el empleo de fusión continua en procesos pirometalúrgicos), ${ }^{18}$ los equipos más grandes y eficientes en minas y plantas, la instalación de plantas de chancado dentro de las minas y las mejoras en el transporte de minerales mediante grandes camiones, minero-ductos y fajas.

La actividad de exploración minera tradicionalmente ha utilizado métodos de perforación diamantina, efectiva para descubrir yacimientos, pero ineficiente para dirigir la explotación. La tecnología geofísicay la exploraciónsatelital proporcionan a la minería información más precisa, que se materializa en menores costos de desarrollo y explotación y en una mayor recuperación de los yacimientos. En lo referente al minado, la minería utiliza tecnologías que le ayuden a mejorar el conocimiento de las rocas, como nuevos explosivos y softwares que simulan la perforación y detonación. La excavación tiende a ser un proceso continuo con mayor automatización de sus operaciones. Todas estas nuevas tecnologías reducen significativamente los costos de explotación de yacimientos.

Las principales instituciones públicas queapoyanla innovación minera son el INGEMMET, que provee al sector mapas geológicos, archivos de informes récnicos, información de ocurrencìs minerales, edades radiométricas, fósiles, geoquímica regional y fenómenos de riesgo geológico; y el Instituto Peruano de Energía Nuclear (IPEN) que entre otros servicios, facilita a la minería diversas aplicaciones minero-ambientales de radiotrazadores, ${ }^{19}$ algunas de sus aplicaciones.

18 Analisis de la Competitividad de la Gran Mineria Metálica del Perit. Lima: Centrum, 2003, p, 10.

19 Elementos químicos que al recibir radiación, permiten la verificación de distintas pruebas como de origen de contaminación y dispersión de contaminantes, filtraciones de relaves y planes de cierre. 
fueron: la evaluación dinámica de filtraciones de relaves en la mina Arcata, determinación de filtraciones en Casapalca, y servicios de Ensayos no destructivos para Antamina.

Algunas de las innovaciones destacadas en los procesos mineros fueron la Planta de tratamiento de aguas ácidas y tratamiento de agua por ósmosis (Yanacocha); la evaluación de alternativas para el tratamiento de minerales con arsénico, planta de cianuración de Uchucchacua, cambios de celdas de flotación para la limpieza de concentrados (Buenaventura); el proyecto de la fundición de Ilo que incluye el uso de hornos rotatorios (Southern), entre otros.

Finalmente, revisaremos la relación y estrategias de las empresas mineras con actores locales. $\mathrm{La}$ principal estrategia de relación es el desarrollo de aglomeraciones productivas en torno a la mina. El tamaño de la aglomeración está definido en función del tamaño de la operación minera; es así como las más importantes están vinculadas con las grandes empresas; destacamos las aglomeraciones relacionadas con Yanacocha, Antamina, Southern, entre otras. Los principales proveedores de estas minas, son los de servicios de energía eléctrica, de maquinarias y equipo minero, de insumos metalmecánicos y combustibles. $^{20} \mathrm{La}$ experiencia de la mina Buenaventura es un caso exitoso en el que una empresa local logra vincularse con una importante empresa multinacional (Newmont).

\section{Capital humano}

El Perú mantiene un liderazgo en el campo de la capacitación en mineria y ha formado durante anios trabajadores en diferentes niveles: ejecutivos, profesionales, técnicos y obreros con experiencia minera. En 1970, la Pontificia Universidad Carólica del Perú inauguró su

20 El complejo de cabre de Southern Peri. Lima: Centrum, 2000. 
facultad de Ingeniería de Minas. A la fecha, existen 16 universidades que ofrecen la carrera de Minas, con aproximadamente 4000 estudiantes de los cuales 400 egresan por año. ${ }^{21}$ La mayoría de estas universidades son públicas, y lamentablemente presentan los problemas típicos de las instituciones formativas en el Perú; presupuesto limitado que incide en el nivel de preparación de los estudiantes y ausencia de laboratorios, reactivos y otros materiales que posibiliten una preparación práctica adecuada.

Una de las principales demandas del sector minero se da a consecuencia de la falta de escuelas mineras de mandos medios. Entre las que existen destaca, según Tecsup, ${ }^{22}$ una organización educativa privada líder en tecnología, con más de 20 años en el mercado. Esta institución fue creada con la participación de empresarios del sector minero y la cooperación internacional, con el objetivo de ofrecer servicios que satisfagan las expectativas del mercado laboral por medio de carreras profesionales.

Ante el crecimiento de la actividad minera durante la última década, ha surgido una variedad de consultorías que proveen distintos servicios. Algunas son consultorías extranjeras, filiales de empresas internacionales como Bechtel y Kilborn. En ellas laboran un buen número de consultores peruanos. Cuando las empresas extranjeras requieren de un servicio más especializado, suelen contratar directamente desde sus casas matrices.

Los consultores peruanos son profesionales que han trabajado en empresas mineras grandes, como Centromín Perú, Southern Perú - Cerro Verde. Sus clientes son también empresas nacionales. De acuerdo con el tipo de servicios que prestan, se ubican aquellos que brindan servicios de exploración y análisis geológico, mineralógico y

21 Cendón, M. Informe del Area de Ingeniería de Minas. Lima: Pontificia Universidad Católica del Perú, 2002.

22 Instituro Tecnológico Superior. 
metalúrgico. Los que brindan servicios ambientales y asesoran en la elaboración de Programas de Adecuación al Medio Ambiente (PAMA) y en Estudios de Impacto ambiental (EIA). Sus clientes son las empresas nacionales y excepcionalmente las empresas extranjeras o el Ministerio de Energía y Minas, quienes les encargan determinadas auditorías. Otros consultores elaboran estudios de prefactibilidad y factibilidad y evaluaciones económicas de proyectos mineros. Existen también servicios legales brindados por estudios de abogados especializados en legislación minera y tributación, cuyos clientes son tanto las empresas extranjeras como nacionales. Hay, además, consultores que asesoran en obtención de fuentes de financiamiento y opciones para captar fondos por medio de oferta pública.

Los profesionales mineros participan en diversas instituciones. Entre las principales están la Sociedad Geológica Nacional, el Instituto de Ingenieros Mineros y el Instituto de Seguridad Minera. Todas estas instituciones realizan eventos anuales, en los que se presentan técnicas, que permiten una gran difusión de nuevos conocimientos e información sobre los principales proyectos u operaciones mineras. Casi todos los profesionales mantienen algún tipo de relación con estas instituciones; de esta forma el recurso humano se mantiene acrualizado.

Las grandes empresas del sector se preocupan por entrenar a su personal en todos los niveles; muchas de ellas han realizado alianzas con importantes escuelas de gerencia con la finalidad de brindar formación de calidad a sus trabajadores; en algunos casos por la distancia del lugar de trabajo, se están desarrollando programas in house (en el campamento minero).

Se debe destacar la labor empresarial de Southern Perú Copper Corporation, empresa reconocida por contar con excelentes programas de capacitación. La compañía, además, ha provisto indirectamente de profesionales a los nuevos megaproyectos como Antamina y Yanacocha. 
Uno de los programas de la empresa es el denominado Gris Gerencial, que consiste en la preparación de altos ejecutivos que luego realizarán la transferencia de los conocimientos adquiridos en sus respectivas unidades funcionales. Los gerentes y personal operativo son enviados al exterior para actualizarse en lo más moderno de la tecnología, al finalizar, realizan informes y difunden el conocimiento al resto del personal, generándose un efecto multiplicador.

Hay distintas políticas sobre el capital humano, en general, las empresas europeas y americanas invierten y valoran más su capital humano, por ello, presentan intensos programas de capacitación $y$ de bienestar de sus trabajadores. Las empresas chinas priorizan determinadas relaciones con algunos grupos de interés externos a la organización y no se comprometen en programas formativos o de bienestar al mismo nivel de las empresas americanas.

Minera Yanacocha, por ejemplo, emplea aproximadamente 2300 empleados de forma permanente, $97 \%$ de los cuales son de nacionalidad peruana y, de éstos, el $49 \%$ son residentes locales. Durante el año 2004, 6745 contratistas trabajaron para la mina. ${ }^{23} \mathrm{La}$ mina empleó a 185 mujeres e invirtió US\$2 200000 en capacitación (US\$ 1000 en promedio por empleado). Yanacocha ha lanzado un nuevo programa LEAD con la participación de 400 gerentes para mejorar el liderazgo, las relaciones con supervisores y con el personal; este es un plan global estandarizado de Newmont cuyo objecivo es desarrollar el liderazgo y la capacidad de gestión de sus gerentes de primera línea y de nivel medio. Otro programa, LeaderQuest, se introdujo el 2004 para desarrollar capacidades en los lideres ya existentes e identificar futuros gerentes. La empresa envió 5 miembros de su personal en Perú a visitar las minas de Newmont en Nevada y su sede corporativa en Colorado.

$2377 \%$ de las empresas que proporcionaron servicios fueron de nacionalidad peruana $y$ el $15 \%$ fueron de base local. 
IMPLICANCIAS DE LA INVERSION EXTRANJERA

DIRECTA EN EL SECTOR MINERO DE PERƯ

Southern Perú emplea 3565 trabajadores permanentes, de ellos $756(21 \%)$ son funcionarios, $1079(30 \%)$ son empleados y 1730 (49\%) obreros; la empresa ahora es propiedad del Grupo México $\mathrm{y}$ ha mantenido los programas formativos implementados por los propietarios americanos.

Shougang mantiene 1880 trabajadores, de los que 1573 permanentes, 239 (15\%) funcionarios, 430 (23\%) empleados y 904 $(62 \%)$ obreros. El gran potencial de reservas de hierro y la creciente demanda mundial del producto. Exigen que la empresa realice mayores inversiones, no solo en infraestructura, sino también en capacitación y bienestar para sus trabajadores.

\section{Características institucionales}

Mediante la promulgación de la Ley General de Minería (Decreto Supremo 014-92 del Ministerio de Energía y Minas), se eliminó la actividad empresarial del estado promoviendo la inversión privada; asimismo, se redujo la intervención y el control estatal sobre la actividad, se declaró de interés nacional la promoción de inversiones en el sector y se establecieron una serie de incentivos a los inversionistas del sector.

El Decreto legislativo 708 (Ley de Promoción de Inversiones en el sector minero) promueve la competitividad internacional de las empresas mineras, la constitución de un esquema de garantías a la inversión y la modernización del régimen de concesiones.

El DL 708 modificó el procedimiento ordinario para obtener una concesión minera y dispuso la implementación del sistema de cuadrículas, elaborado sobre la base de las Cartas Nacionales emitidas por el Instituto Geográfico Nacional. El objetivo era elaborar un inventario de los derechos mineros (Catastro Minero), con el apoyo de un documento cartográfico que respalde la ubicación física en el 


\section{PRINCIPALES INCENTIVOS A LA INVERSION MINERA}

- Estabilidad tributaria, cambiaria y administrativa.

- La tributación grava únicamente la renta que distribuyen titulares de actividad minera.

- El estado reconoce la deducción de tributos que inciden en la producción.

- Las inversiones aprobadas por la autoridad en infraestructura de servicio público son deducibles de la renta neta.

- No discriminación en materia cambiaria y otras medidas de política económica, respecto a inversionistas nacionales $\mathrm{u}$ otros sectores de actividad económica.

- Libertad de remitir utilidades, dividendos y recursos financieros y libre disponibilidad de moneda extranjera.

- Libre comercialización de los productos minerales.

- Simplificación administrativa

Fuente: Ley General de Mineria (D. S. 014-92)

territorio. Con este nuevo sistema se simplificó el trámite de obtención de concesiones, facilitando la inversión.

Las nuevas disposiciones técnicas y legales han permitido asimismo, el rápido aumento de hectáreas en fase de exploración minera. En 1991, se exploraban 10 millones de hectáreas; en 1998, 17 millones. Una cantidad importante de los nuevos petitorios fueron realizados por compañías internacionales como RTZ (Reino Unido); Asarco, Newmont, Phelps Dodge y Cyprus-Amax (EE.UU.); Anglo 
American (Sudáfrica); Glencore (Suiza); Newcrest y Broken Hill Propietary (Australia); Teca Corp, Cambior, Noranda, Placer Dome y TX (Canadá).

El Texto Único Ordenado de la Ley General de Minería define las normas para la suscripción de contratos de estabilidad tributaria. Existen dos tipos de contratos: el primero de ellos se aplica a los inversionistas mineros que inicien operaciones mayores de $350 \mathrm{TM} /$ día hasta $5000 \mathrm{TM} /$ día; los inversionistas deberán presentar programas de inversiones superiores a los US\$ $\$ 2$ millones. El plazo de los contratos es de 10 años. La segunda modalidad de contrato está destinada a promover la inversión y facilitar el financiamiento de los proyectos mineros con capacidad inicial no menor a $5000 \mathrm{TM} /$ día o de ampliaciones destinadas a lograr esta capacidad. Los inversionistas deberán presentar programas de inversión no menores a US\$20 millones cuando se trate de nuevos proyectos. Para el caso de empresas existentes, el programa no podrá ser inferior a US\$ 50 millones; el plazo es de 15 años. Estos contratos adicionalmente permiten ampliar la tasa anual de depreciación de las maquinarias, equipos industriales y demás activos fijos hasta el límite máximo de $20 \%$ anual.

Los contratos de estabilidad tributaria suscritos por el gobierno alcanzan la suma de US $\$ 3097$ millones hacia diciembre de 1998, entre los contratos más importantes destacan los de Antamina (US\$ 1929 millones), Barrick (US\$ 249 millones), The Doe Run (US\$ 85 millones), Cerro Verde (US\$ 237 millones), Southern Copper Corporation (US\$ 118 millones).

Otra medida promotora fue gravar únicamente la renta que distribuyen los titulares de la actividad minera. La renta no distribuida se aplicará a nuevos programas de inversión, garantizando con ello el incremento de los niveles de producción de las empresas mineras. 
Otro incentivo a la inversión minera fue la devolución del impuesto general a las ventas, que en el Perú es del $19 \%,{ }^{24}$ por concepto de adquisiciones de bienes y servicios que realicen las empresas mineras. Asimismo, los gastos de prospección y exploración serán deducibles en el ejercicio en que se incurran dichos gastos, mediante esta disposición la Ley incentiva la exploración y prospección.

La Ley permite también deducir de la renta imponible las inversiones que se efectúen en infraestructura de servicio público, tales como: obras viales, puertos, aeropuertos, salud, vivienda, telecomunicaciones, entre otras. Las empresas mineras tampoco están afectas a los tributos municipales sobre las edificaciones necesarias para la actividad minera.

En diciembre de 1995, se modificó el artículo 7 de la Ley de Tierras, que norma el proceso de indemnización en efectivo del propietario agrícola por el titular de la actividad minera. La disputa por la superficie de las tierras, que en gran parte pertenecen a comunidades de la Sierra (asentadas por siglos en esos territorios), ha sido uno de los temas por resolver, a tal punto que existen comunidades campesinas que objetan la Ley, produciéndose litigios legales y enfrentamientos entre los inversionistas mineros y las comunidades campesinas.

Dos instituciones del Gobierno, Proinversión y el INGEMMET, han facilitado información y orientado a potenciales inversionistas del sector, la inversión en minería no solo requiere recursos económicos significativos sino que demanda gran cantidad de tiempo en sus fases de concesión y exploración. La ayuda, tanto de Proinversión como de INGEMMET, ha permitido simplificar los trámites administrativos en las concesiones $\mathrm{y}$, en el caso de INGEMMET, facilitar mapas geológicos y cartografías de gran utilidad.

24 Incluye el impue o de promoción municipal (2\%). 
Estas medidas de promoción han contribuido al incremento del interés por explorar en el país, existen a la fecha 5052 aplicaciones de derechos mineros ${ }^{25}$ y un nivel de inversión de las compañías mineras de aproximadamente US\$1000 millones. $^{26}$

Sin embargo, el potencial del Perú en minería es todavía parcialmente aprovechado, como refiere el instituto Fraser en su Informe Anual 2005-2006 sobre las compañias mineras: el Perú ha descendido en el ranking de Policy Potencial, del puesto 39 el аб̆о anterior al 44 (de un total de 64 paises y regiones); este ranking mide el nivel de atractividad de las políticas de promoción minera.

El mismo estudio permite observar que, si se asumiera que no existen restricciones en la tenencia de tierras y que la industria utiliza las mejores prácticas, el país se ubicaría en el primer puesto en el ranking de potencial minero: el potencial geológico es muy grande y las políticas gubernamentales no logran rescatar todo su valor. El Informe Fraser, además, ayuda a identificar áreas potenciales de mejora, al mostrar bajo diferentes criterios la posición relativa del país en sus diversos rankings, como son confiabilidad en las regulación (puesto 41), duplicidades e inconsistencias regulatorias (puesto 36), incertidumbre sobre reclamos de tierras por comunidades (puesto 51), acuerdos socioeconómicos (puesto 56), estabilidad política (puesto 56), regulaciones laborales (puesto 38), seguridad (puesto 58).

Consistentemente con estos resultados, los empresarios entrevistados observaron como debilidades institucionales del sector, la falta de seguridad, el marco regulatorio, los reclamos de las comunidades, la inestabilidad política y las limitaciones en infraestructura.

25 Instituto Nacional de Concesiones y Catastro Minero 2005.

26 Banco Central de Reserva del Perú. 


\section{WILLIAM MUNOZ MARTICORENA}

Sin embargo, algunos de los empresarios consideraron que el gremio empresarial, la Sociedad Nacional de Minería y Petróleo, debiera también replantear su visión y dar mayor importancia a los valores corporativos, a la responsabilidad social empresarial y al desarrollo de una estrategia nacional para el sector.

\section{Responsabilidad social corporativa}

La Responsabilidad Social Corporativa (RSC) se entiende como una filosofía puesta en práctica por las empresas, orientada a la satisfacción de los consumidores, trabajadores y sus familias y al entorno en el que operan.

Para efectos de análisis, entendemos que Responsabilidad Social Corporativa es el mecanismo por medio del cual, las empresas transnacionales se insertan (para desarrollar sus actividades) en un conjunto de reglas o estándares mínimos: laborales, ambientales y de salud $y$, de relaciones con la comunidad, que deben ser cumplidas íntegramente en su estructura organizacional $y / o$ a lo largo de su cadena productiva. Este conjunto de reglas se derivan de las normas internacionales de derecho público reconocidas en los tratados internacionales sobre derechos fundamentales en materia laboral, ambiental o de salud.

Uno de los instrumentos mediante el cual se mide la RSC es el Código de Conducta, en Perú, la Sociedad Nacional de Minería, Petróleo y Energía (SNMPE) ha implementado su Código de Conducta el 2002, en él refieren que sus actividades productivas respetarán la legislación vigente en el país, que armonizarán sus intereses empresariales y productivos en la búsqueda de una vida digna y desarrollo sostenible en la sociedad, custodiarán la salud y la seguridad, protegerán el medioan biente, harán uso adecuado de los recursos naturales y respetarán las diversidades étnicas. 
Todas las empresas mineras, sean extranjeras o nacionales, están afiliadas a la SNMPE, y deben cumplir con el Código. Asimismo, una gran parte de estas empresas participan en Perú 2021, ${ }^{27}$ siendo el sector minero, de esta manera, bastante informado y comprometido con la RSC.

Un estudio de Baltazar Caravedo, ${ }^{28}$ identificó que durante el período 1997-1998 se produjo un incremento en el porcentaje de empresas que mantenían políticas proactivas de inversión social, el incremento fue de $29 \%$ a $49 \%$. La investigación mostraba que fueron precisamente las empresas mineras las que presentaron mejores resultados, de $48 \%$ ascendieron hasta $70 \%$. Otros sectores, como el manufacturero y el de servicios, alcanzaron $63 \%$ y $33 \%$ respectivamente en 1998 .

Todas las empresas afiliadas a la SNMPE informan sobre su gestión social y ambiental, señalando el modelo de gestión utilizado, tanto en el trabajo como en las relaciones comunitarias, sus iniciativas de desarrollo de diálogo y concertación, así como la evolución de sus indicadores de gestión ambiental, la calidad de los efluentes líquidos y del aire.

En lo que se refiere a las relaciones de las empresas con sus trabajadores, la totalidad de ellas afirmaron ofrecer beneficios adicionales a sus trabajadores, preferentemente reconocimientos y premios, capacitación y actividades extra-laborales. El promedio de gasto en capacitación fue de US\$900 000, y el número de personas capacitadas, 400. Las principales temáticas de capacitación fueron seguridad, gestión y operaciones. Destacó Yanacocha con un gasto de US\$2 200 millones en capacitación y 2280 trabajadores capacitados

27 Asociación civil sin fines de lucrolque busca la difusión y promoción de la Responsabilidad Social (RS) como metodologia de gestión empresarial.

28 Chravedo, Baltazar, Lo Social y la Empresa a fines de Siglo. Responsabilidad Social. Empresarial: avances y logros. Lima: SASE/Perú 2021, 1999. 
Los conflictos entre comunidades y empresas mineras fueron resaltados por los medios de comunicación en años recientes. Los problemas más serios fueron los de Tambogrande (Mina Manhattan) y Cerro Quilish (Yanacocha). En ambos casos, las comunidades lograron detener la puesta en marcha de inversiones mineras que habían sido autorizadas por el Ministerio de Energia y Minas (MEM). Estas comunidades que viven en zonas muy retiradas y de gran altura, por lo general nunca han sido atendidas por el Estado, ven a la empresa minera como el interlocutor para todas sus quejas y como el proveedor de todos los servicios básicos que, como ciudadanos, deberfan tener derecho. Existe mucha falta de conocimiento y, por tanto, de desconfianza.

El tema de la contaminación es frecuente en los conflictos mineros, todas las actividades económicas son contaminantes, pero la minería por los volúmenes que desplaza tiene un impacto mayor sobre el medio ambiente. A pesar de que muchas empresas mineras cumplen con la legislación ambiental vigente, los impactos se van a dar debido a que las normas y reglamentos dedican poca atención al proceso de acumulación de residuos y por la mala definición de los límites permisibles por la ley y la calidad ambiental mínima requerida por los pobladores, ${ }^{29}$

Muchos de los conflictos mineros se originan por falta de transparencia en las negociaciones y por el beneficio personal de unos pocos. Hay más de un conflicto por la cesión de terrenos por parte de los directivos de las comunidades que luego son desconocidos por el resto de la comunidad porque nunca fueron informados de ello.

Frente a esta problemática, las empresas mineras deben ser rigurosas en el seguimiento de los protocolos de información previa a las comunidades; asimismo, deben exigir al estado que las acompañe en

29 Kuramoto, Juana. "Conflictos mineros en el Perú: Retos y Oportunidadesn. Horizonte Minero, n. 29 , octubre - noviembre, 2004. 
esta labor fungiendo de fedatario. No es posible iniciar operaciones en tierras de una comunidad sin licencia social, desde el primer día debe existir un diálogo transparente con la comunidad, se deben explicar las características principales del proyecto minero, los impactos positivos y negativos para la comunidad, el proceso a seguir para su ejecución y las competencias de las entidades en ese proceso.

Por ouro lado, las empresas, en particular, las extranjeras, suelen llegar muy desinformadas sobre la realidad socioeconómica de la región. Deben entender que su misión es promover el desarrollo sostenible, aplicando políticas de RSC, buscando un equilibrio entre sus resultados operativos y financieros, y el cumplimiento de su Responsabilidad Social y Ambiental.

Producto del diálogo y la negociación, se puede obtener la Licencia Social, que es un acuerdo de intereses entre la comunidad y la empresa, también constituye un requisito indispensable para hacer factible la actividad productiva. Los directivos de Antamina consideran que es un requisito ético, que asegura una relación armoniosa con el entorno, que facilita las condiciones para la producción, es una propuesta gana-gana y una inversión rentable.

Es evidente que las empresas no llegaron preparadas para resolver problemas con las comunidades indígenas, sin embargo, con el tiempo están aprendiendo a relacionarse cada vez mejor. Prueba de ello son los proyectos de reciente implementación como Antamina y Las Bambas, que han seguido el proceso correctamente, obteniendo primero su Licencia Social y luego realizando contribuciones importantes a la comunidad.

Actualmente, la mayoría de las grandes empresas contribuyen con donaciones, en mejora de la infraestructura, eventos deportivos, culturales y brindan asistencia técnica. Sin embargo, difieren entre ellas, en los montos de inversión asignados para estas iniciativas, así como en la dimensión de sus programas; por ejemplo, Las Bambas, 
apenas suscribió el Contrato de Opción, efectuó la transferencia de US\$ 45500 millones a la comunidad mediante el mecanismo del Fideicomiso Social. Antamina aportó US\$ 111 millones a la Asociación Ancash, para que promueva el desarrollo sostenible en su área de influencia. Yanacocha ayuda a la Asociación Los Andes de Cajamarca.

Todas las empresas mineras participan en la SNMPE; las más importantes participan, asimismo, en Perú 2021 y dependiendo de su origen, en su Cámara de Comercio Binacional correspondiente.

La mayoría de empresas estiman conveniente establecer relaciones de largo plazo con sus proveedores; sin embargo, los proveedores locales que cumplen con determinados estándares de

\section{Fideicomiso Social Las Bambas}

El fideicomiso Social Las Bambas nació como compromiso establecido en el proceso de inversión del proyecto Las Bambas. Suscribiéndose el contrato de opción el 1 de Octubre del 2004, con lo que se hizo efectivo por parte del Estado el primer aporte al Fideicomiso Social Las Bambas, ascendente a US\$ 45500 000 destinados exclusivamente para proyectos de inversión social en las provincias de Cotabambas y Grau.

A través de los mecanismos de mesas de diálogo y presupuesto participativo lograron elegir y dar prioridad a los proyectos de inversión social en cada comunidad, el Consejo Directivo del Fideicomiso Aporte Social Las Bambas, está integrado por 5 alcaldes, 2 consejeros regionales, 1 representante de XSTRATA y un representante de Proinversión. A la fecha están ejecutándose o pendientes de ejecución, más de 50 proyectos para una vida digna en Grau y Cotabambas. Entre ellos: 
IMPLICANCIAS DE LA INVERSIÓN EXTRANJERA

DIRECTA EN EL SECTOR MINERO DE PERÚ

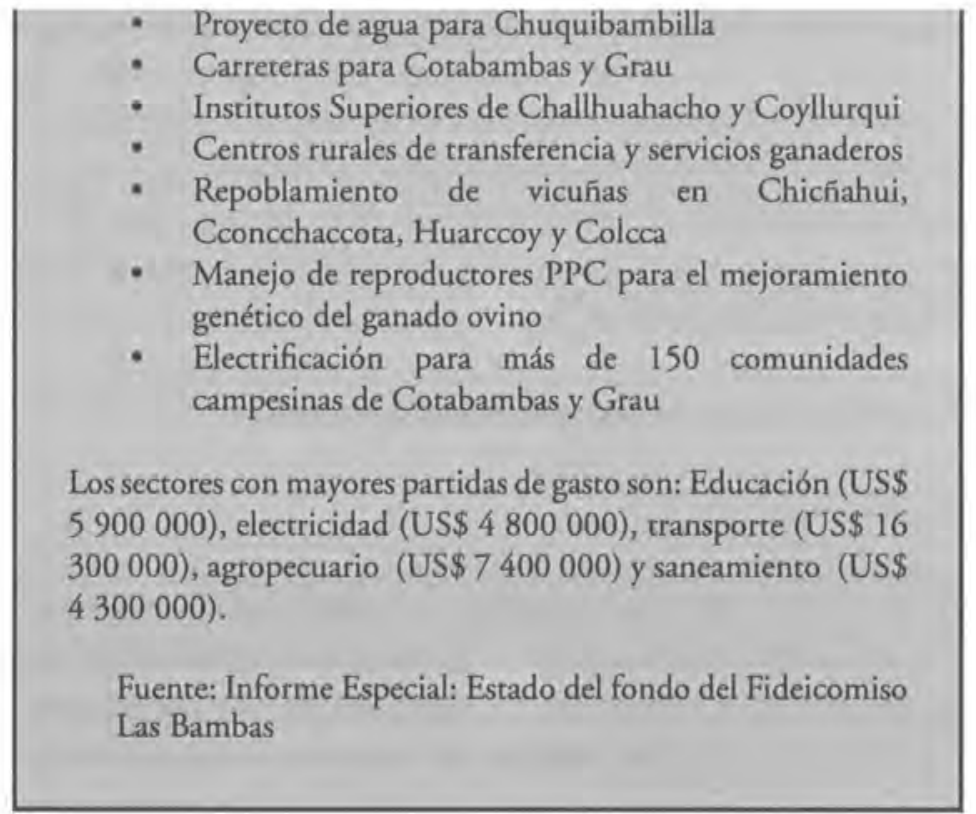

especialización y productividad son escasos y no están alineados a estándares internacionales. En especial, aquellas empresas certificadas con ISO 14001 y SA 8000, van a ser más exigentes al momento de calificar proveedores (BHP-Billiton, Antamina, Yanacocha, Barrick, Southern).

El mercado del sector minero es un mercado de commodities, los clientes son operadores en los mercados de Londres y Nueva York, y es usual también que se coloquen producciones a futuro. El producto es muy estandarizado.

En el sector minero, muchas políticas de seguridad tienden a cuidar la salud de los trabajadores, todas las minas disponen de señalizaciones, protectores y barreras de seguridad. En Las Bambas, Antamina, Yanacocha, y en general en la mayoría de minas se 
disponen de procedimientos escritos de trabajo seguro y programas de seguridad. Las políticas ambientales en el sector minero tienden a minimizar el impacto ambiental en la etapa de exploración, todas las minas sin excepción están obligadas a elaborar su programa de manejo ambiental (PAMA) para sus operaciones, a fin de vigilar su cumplimiento se realizan monitoreos ambientales en el área de influencia de las operaciones.

\section{Conclusiones y recomendaciones de expertos}

\section{Conclusiones}

El Perú posee una riqueza notable en yacimientos de minerales, de la que se aprovecha solo una pequeña porción. La actividad minera requiere de grandes inversionistas por la naturaleza de sus operaciones. Fue, precisamente, para atraer este tipo de empresariado que sé diseñó la Ley de Minería de 1992, que mediante una combinación creativa de medidas e incentivos, volvió atractiva la exploración y explotación en el país.

La demanda internacional por minerales se ha incrementado en años recientes, la recuperación de las economías americanas, europeas y japonesas, así como el acelerado crecimiento de la China y la India explican esta expansión. Las proyecciones de expertos señalan que los precios subirán un poco más debido a que se están generando brechas entre oferta $y$ demanda de algunos minerales, específicamente el cobre y el zinc. La tendencia de la cotización del oro también es hacia arriba. En este contexto, no queda sino continuar explorando para que con nuevos yacimientos podamos capitalizar la coyuntura.

Chile proyecta para el 2006 exportar cobre por US\$27000 millones y generar ingresos fiscales por minería del cobre por US $\$ 11000$ millones, es decir, obtener solo en impuestos, el equivalente al 120\% de las exportaciones peruanas de minerales del 2005. 
Los clusters son espacios donde se pueden apreciar con más facilidad las tareas pendientes para mejorar un sector. En Perú, una aglomeración minera conocida ha sido Centromín Perú, sin embargo, en años recientes, con la llegada de megaproyectos mineros, surgen nuevas aglomeraciones en torno a éstos. Hay que observar entonces la calidad de los proveedores, la eficiencia de las instituciones de apoyo, como Ministerios, catastro, INGEMMET, las Municipalidades, Proinversión, las universidades, entre otras. Porque de la observación de las brechas y de las falencias surgen las oportunidades de mejora, no solo para la empresa individual sino para toda la aglomeración.

Sobre la innovación y la tecnología, es claro que hay que fortalecer la investigación y el desarrollo, pero siempre vinculando a la universidad y la empresa.

El informe Fraser 2005-2006, revela problemas del país para atraer inversión hacia la minería, específicamente, por problemas de desconfianza en la regulación, incertidumbre sobre reclamos de tierras de las comunidades, estabilidad política y seguridad, éstos son algunos de los principales problemas que impiden que el Perú sea más atractivopara la inversión extranjera.

Un sector del empresariado demanda repensar el rol de la SNMPE, reclamando un mayor compromiso con la RSC y una nueva visión estratégica.

El sector minero, es el más informado de todos los sectores sobre la RSC, de una u otra forma, todas las empresas mineras realizan alguna iniciativa de responsabilidad social, sin embargo, existen aquellas empresas que hacen filantropla, y ouras que están aprendiendo a relacionarse con comunidades indígenas, para las que la RSC constituye una inversión que redundará en el sostenimiento a largo plazo.

Existen experiencias valiosas e instrumentos elaborados para las empresas que deseen invertir en el Perú, en las alturas y en tierras de comunidades campesinas. 


\section{Recomendaciones de expertos}

Hay un experto que considera que es suficiente la riqueza geológica del país para atraer inversión, sin embargo, reconoce que el principal obstáculo al crecimiento de la inversión extranjera es el gobierno, por la burocratización, la corrupción y el poco apoyo a la innovación. Otro experto observa el peligro para el medioambiente que significan las pequeñas empresas mineras, las cuales son las más contaminantes. Un experto refiere, que estos son los mejores momentos para explorar y realizar alianzas o vender los derechos de explotación.

Refieren que las limitaciones o tareas pendientes, evidenciadas por el Informe Fraser, deben ser tomadas en cuenta y corregidas, particularmente, los aspectos de seguridad, de confiabilidad en la regulación y de reclamos de tierras por las comunidades, debieran ser trabajados cuanto antes.

Sobre las relaciones con las comunidades, una experta comenta que las empresas deben entender que la actividad minera se realiza en las zonas más pobres del Perú, donde hay una ausencia del Escado. Por tanto, tienen que tener presente que el tipo de responsabilidad social que ejerzan en esas zonas es totalmente distinto al que ejercen en sus paises de origen. Esto implica un mayor compromiso con las comunidades $y$, por otro lado, una presión política para que el estado en todos sus niveles comience a ser un actor importante. Se sugiere sustituir el capital natural que se extrae por capital físico, humano y social.

$\mathrm{El}$ gremio minero debe exigir a sus empresas mantener unos estándares de manejo ambiental aceptables y que mejoren con el tiempo, la experiencia señala que el aumento de los estándares ambientales ha generado cambios tecnológicos que han elevado la productividad de las empresas. 


\section{IMPLICANCIAS DE LA INVERSION EXTRANJERA \\ DIRECTA EN EL SECTOR MINERO DE PERU}

Se debe exigir la transparencia de los indicadores ambientales que mantiene el MEM, su difusión permitirá identificar qué empresas cumplen con las regulaciones y cuáles no.

Debe existir una política de formación de proveedores locales y nacionales, en este esfuerzo debieran contribuir otras instituciones de la sociedad civil como, las cámaras de comercio, el gremio industrial $\mathrm{y}$ las universidades.

Las empresas mineras y su personal deben mantener códigos de conducta sumamente estrictos en cuanto a sus relaciones formales e informales con la población local.

\section{Bibliografía}

Brugnoli, Alberto. FDI in Latin America and private sector development: Issues for institutional Capacity building in three Andean countries. Milán: Universidad Luigi Bocconi, 2006.

Campodónico, Humberto. Las reformas estructurales en el sector minero peruano y las caracteristicas de la inversión 1992-2008. Lima: CEPAL, 1999.

Campodónico, Humberto; Georgina Ortiz. Caracteristicas de la inversión y del mercado mundial de la minería a principios de la década de 2000. Santiago: CEPAL, 2002.

Consultorn Macroconsult. El sector de la Minería en Perí, Informes sectoriales. Lima; ICEX, 2005.

Cuanto. Anuario Estadistico Perú en Números 2005. Lima: Cuanto S.A., 2005. 


\section{WILLIAM MUNOZ MARTICORENA}

D'Alesio Ipinza, Fernando. Análisis de la Competitividad de la Gran Mineria Metálica del Perú. Lima: CENTRUM Católica, 2003.

Garavito, Cecilia. Consultoria sobre cumplimiento de estdindares sociales y responsabilidad social empresarial en empresas transnacionales. Lima: Plades, 2004.

Indacochea, Alejandro. Cajamarca competitiva. Lima: Saywa Ediciones, 1998.

Kuramoto, Juana. Las aglomeraciones productivas alrededor de lat mineria: El caso de la minera Yanacocha. Santiago: CEPAL, 2000.

McMaнon, Fred. Fraser Institute Annual Survey of Mining Companies 2005-2006. Vancouver: Fraser Institute, 2006.

Preinversión. Guia de Inversiones en el Perú 2005. Lima, 2005.

Porter, Michael. The Competititve Advantage of Nations. Boston: The Free Press, 1998.

PWC. Production Cost Reporting Survey. A survey of production cost reporting practices in Australian Minig industry, Global Energy and Mining Group, 1998.

SNMPE. Memoria Annual 2005. Lima, 2006. 